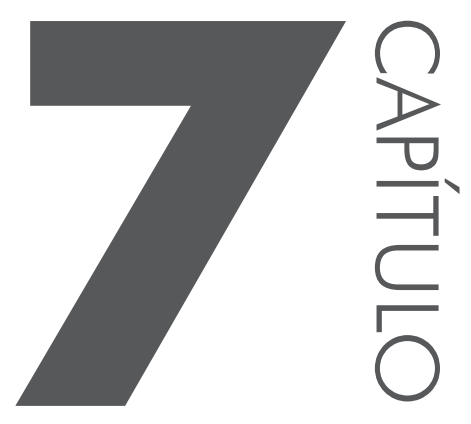

\title{
Avaliação e variação linguística: estereótipos, marcadores e indicadores em uma comunidade escolar
}

Raquel Meister Ko. Freitag

Cristiane Conceição de Santana

Thais Regina Conceição de Andrade

Valéria Santos Sousa

\subsection{INTRODUC̣ÃO}

O falante está em constante processo de avaliação da língua, seja de forma consciente ou não. No processo da variação, embora tenham o mesmo valor de verdade ou representacional, às formas linguísticas diferentes podem ser atribuídas avaliações ou valorações sociais igualmente diferentes, o que se dá por conta das pressões sociais que operam constantemente sobre a língua, "não de algum ponto remoto no passado, mas como uma força social imanente agindo no presente vivo" (LABOV, 2008, p. 21).

Quanto à avaliação social, Labov (2008) trata de três categorias: os estereótipos, que são os traços linguísticos socialmente marcados de forma consciente pelos falantes; os marcadores, que são os traços linguísticos sociais e estilísticos e que permitem efeitos consistentes sobre o julgamento consciente ou inconsciente do ouvinte sobre o falante; e os indicadores, que são os traços socialmente estratificados, no entanto, não são sujeitos à variação estilística. 
Em contextos de interação, a avaliação social se faz mais saliente; fatores de ordem pragmática, como a expressão da polidez - uma atividade estratégica racional, decorrente da necessidade que o homem tem de manter o equilíbrio em suas relações interpessoais, levando-o a usar um conjunto de estratégias linguísticas, a fim de evitar ou reduzir ao mínimo o conflito com seu interlocutor (BROWN; LEVINSON, 1987) -, que influencia fortemente tal processo, na medida em que se constrói um processo de construção e preservação de face, pois o outro só poderá ser conhecido a partir do que revela ser. Na proposta de Brown e Levinson (1987), a face que apresenta o lado negativo está relacionada à nossa intimidade e ao desejo de não imposição, enquanto a face que apresenta o lado positivo se relaciona à imagem que queremos passar socialmente, que queremos apresentar aos outros, com o intuito de ter o reconhecimento ou aprovação. A face que apresentamos para o outro nas interações que estabelecemos é o que faz com que nossa autoimagem seja construída socialmente, já que, segundo os autores, as interações são as situações mais propícias para os conflitos, e é justamente nessas situações que buscamos proteger nossa face contra possíveis danos quando interagimos com os outros. Esses danos podem ser causados pelos atos que ameaçam as faces, tanto do falante quanto do ouvinte, no momento das interações.

O modo como uma variante linguística é avaliada socialmente por um indivíduo ou determinado grupo pode implicar na construção da face daqueles que fazem uso ou não de tal variante linguística, pois os interlocutores procuram ao máximo preservar tal face. Uma das estratégias de preservação de faces é o monitoramento linguístico. A fim de testar esta hipótese, investigamos o comportamento de variáveis de estereótipo (traços socialmente marcados de forma consciente), marcador (traços linguísticos social e estilisticamente estratificados, que produzem respostas regulares em testes de reação subjetiva) e indicador (traços socialmente estratificados, mas não sujeitos à variação estilística, com pouca força avaliativa) (LABOV, 2008). Os dados que subsidiam a análise foram coletados no Colégio Estadual Atheneu Sergipense, que constitui a amostra de Aracaju/SE do banco de dados Falares Sergipanos (FREITAG, 2013).

\subsection{FENÔMENOS SOB ANÁLISE}

Escolhemos três fenômenos variáveis do português para investigação: a realização africada de oclusivas alveolares seguintes ao glide palatal, a variação na primeira pessoa do plural e o alçamento de vogais médias a altas. 


\subsubsection{REALIZAÇÃO AFRICADA DE OCLUSIVAS}

A realização africada das oclusivas alveolares $/ \mathrm{t} / \mathrm{e} / \mathrm{d} /$ antecedidas por glide palatal, como nas palavras /muito/ e /muito/, /doido e /doido/, é um traço associado ao falar da região nordeste como um todo, mas mais expressivo em Sergipe, Alagoas e interior da Bahia. A distribuição de frequência de uso quanto aos perfis sociodemográficos de estratificações sociais amplas sugere que o traço é um estereótipo, nos termos de Labov (2008), por ser predominante no conjunto de indivíduos de menor escolarização e de maior faixa etária.

Em estudo anterior (FREITAG, 2015), em uma comunidade de práticas no interior do estado de Sergipe caracterizada pelas polarizações de escolaridade e faixa etária, evidenciamos que a variante africada é um estereótipo.

Como o fenômeno em análise é visto com estigma, os falantes, por hipótese, procuram apresentar para o seu ouvinte a sua face positiva, pois é a partir do que se vê ou ouve que construímos a imagem do outro. Vejamos o excerto (1), retirado da amostra da comunidade do Atheneu Sergipense, que evidencia o juízo estigmatizado atribuído à variante africada.

(1) Doc: Na língua portuguesa a questão da variação linguística que você pode falar que uma mesma palavra tem várias pronúncias mas que é o mesmo significado por exemplo... quando você fala biscoito você vai entender o que é que eu estou pedindo a você e se eu falar biscoito você vai entender o que eu tou pedindo a você mas essa diferença que tem entre uma palavra e outra essa diferença sonora o que você acha? Se você no seu grupo da escola falasse assim?

ELE-F: ah seria zuação porque as pessoas quando você fala uma palavra errada elas começam a zuar

Doc: aí se eu começasse a falar aqui oitenta carros se eu tivesse oito reais. ELE-F: acabam zuando vira motivo de zuação quando fala você alguma palavra que eles não estão acostumados a ouvir palavras diferentes principalmente se você era do interior e veio para cidade e você começa a falar quer queira quer não você sempre pega um pouco do sotaque do local de onde você mora então quando você começa a usar aquele sotaque do interior aqui você acaba sendo discriminado então você tem que se adaptar ao máximo ao modo como as pessoas naquele novo determinado local. (ELE-F, E-A)

O excerto, parte de questões de atitudes linguísticas que compõem o roteiro de entrevista sociolinguística adotado na coleta de dados da amostra, evidencia que a realização africada não é bem aceita dentro do grupo, o que nos leva a uma 
investigação mais aprofundada acerca da ocorrência do fenômeno em análise no repertório linguístico desta comunidade.

\subsubsection{VARIAÇÃO NA PRIMEIRA PESSOA DO PLURAL}

O português brasileiro contemporâneo apresenta sistemática preferência pela forma variante a gente em relação à forma canônica nós (LOPES, 1998). A maioria das gramáticas não apresenta a forma a gente como pronome pessoal, embora algumas mais atuais salientem, ainda que de forma sutil, o processo de gramaticalização dessa forma inovadora.

Com relação à não formalidade de a gente, Campos (2008) mostra que os pronomes nós e a gente ocorrem no português culto falado no Brasil, ou pelo menos na cidade de Belém, com funções pragmáticas diferentes e não apenas relacionadas ao grau de formalidade, como é o caso das entrevistas televisivas. Estudos têm demonstrado que há um favorecimento por parte das mulheres no uso de a gente (ZILLES, 2005; MENDONÇA, 2012; SANTOS, 2014, entre outros) e também da escolaridade: falantes mais escolarizados tendem a utilizar mais a variante inovadora, enquanto os menos escolarizados mantêm o uso da forma canônica.

Temos por hipótese que, assim como mostram estudos anteriores, o uso da forma variante a gente tem comportamento de marcador, sensível à avaliação social, em contextos de maior monitoramento e formalidade.

(2) Doc: Você acha então melhor usar o nós em relação ao a gente?

MAY-F: é sim pode ser mas também falo a gente só com amigo... mas assim diferenciar o a gente () as vezes eu utilizo eu prefiro utilizar o nós mas não me importo não. (MAY-F 17 E-A)

Esse tipo de atitude linguística reforça a premissa de que a variação na primeira pessoa do plural, na comunidade sob análise, tem comportamento de marcador.

\subsubsection{ALÇAMENTO DE VOGAIS MÉDIAS A ALTAS}

O alçamento vocálico é um fenômeno fonológico que se caracteriza pela elevação do traço das vogais médias [e] e [o] que se realizam como vogais altas [i] e [u], ocorrendo variavelmente. Estudos realizados em torno do alçamento de vogais médias e altas, tanto na posição postônica como pretônica, apontam resultados sociais diatópicos diferenciados, considerando a natureza heterogênea e variável da língua. 
O alçamento das vogais médias e altas, postônicas e pretônicas, pode ocorrer diante dos nomes e grupos verbais, podendo ser resultado dos processos de harmonização vocálica (BISOL, 1981), onde a presença de uma vogal alta na sílaba seguinte à da pretônica pode levar à aplicação do alçamento, como em invisti e sufrido; e redução vocálica (ABAURRE-GNERRE, 1981), em que a consoante antecedente à pretônica influencia na realização do processo, como em p[ik]eno. Ambos os casos configuram variação dialetal do português brasileiro. A harmonização favorece a elevação das vogais médias e altas que se encontram constantemente implicadas no processo fonológico que modifica o sistema vocálico, de maneira que a consoante antecedente das vogais médias pode influenciar no alçamento. Além do mais, a sílaba pretônica apresenta um marco importante na constituição e caracterização dialetal no português brasileiro. $\mathrm{Na}$ região nordeste, o alçamento é recorrente (CARDOSO, 1999), tendo como destaque a capital baiana.

Os estudos anteriores sugerem que o alçamento das vogais pode ocorrer por conta das motivações internas da língua, mas com matizes diatópicos. Por isso, esperamos encontrar um comportamento estável na comunidade analisada, como indicador.

\subsection{O ATHENEU SERGIPENSE}

O Colégio Estadual Atheneu Sergipense é a mais tradicional instituição de ensino de Sergipe. Fundado em 1871, inicialmente era uma escola secundária e preparatória para o curso superior e o Curso Normal de formação de professores. No ano de sua fundação, 117 alunos foram matriculados nesses cursos (ALVES, 2005).

Ao longo da sua história, firmada na formação da sociedade sergipana, o Colégio Estadual Atheneu Sergipense não só mudou de sede como também de nome: durante o governo de Maurício Graccho Cardoso, em 1932, o colégio se mudou para o prédio localizado na Avenida Ivo do Prado, onde hoje funciona o Museu da Gente Sergipana. No ano de 1938, durante o Estado Novo, o colégio recebeu a denominação de Colégio Estadual de Sergipe, funcionando na sede da Ivo do Prado até 1950.

A instituição contribuiu significativamente para a formação da sociedade de Sergipe: seus alunos se tornaram professores, governadores, deputados, senadores, prefeitos, empresários e médicos, dentre muitos outros profissionais reconhecidos. 

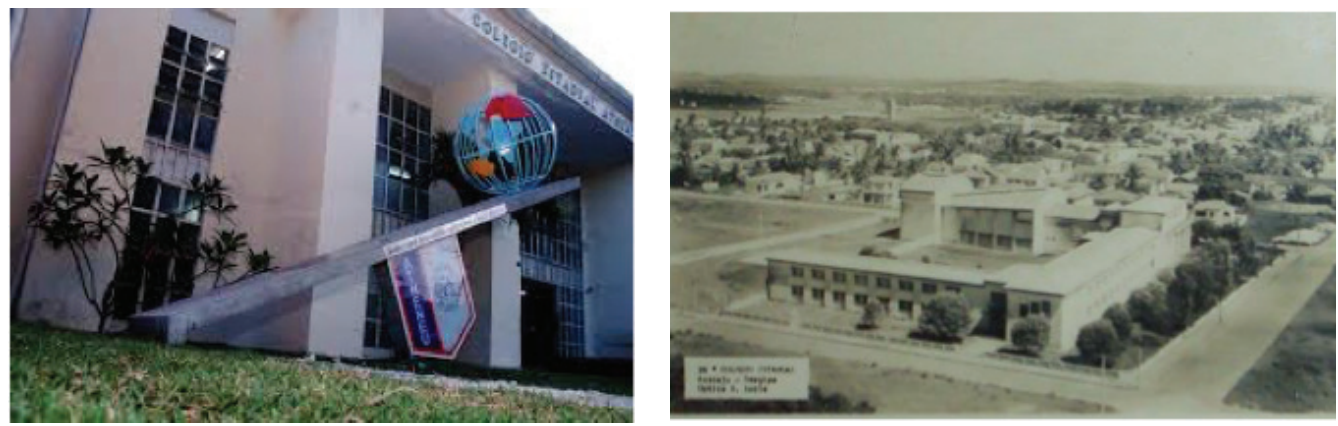

Figura 7.1 - Atheneu Sergipense atualmente (esquerda) e em 1950 (direita). Fonte: Acervo CEMAS.

Atualmente, a escola está localizada no Largo Graccho Cardoso, bairro São José, na zona Sul de Aracaju, Sergipe. A mudança de sede aconteceu durante o governo de José Rollenberg Leite (1975-1979). A escola foi considerada Centro de Excelência no ano de 2003 e nela hoje funciona um Centro de Estudos Experimentais, com a modalidade de educação integral.

A instituição atende apenas ao ensino médio, com catorze turmas do $1^{\circ}$ ano, oito do $2^{\circ}$ ano e cinco do $3^{\circ}$ ano, com cerca de 1.100 alunos, em 2014. O corpo docente é formado por 34 professores que, além de terem o vínculo efetivo no estado, passam por uma seleção para poderem lecionar na escola. A instituição oferece o ensino regular e conta com uma matriz curricular com disciplinas optativas, projetos direcionados à área das artes, educação física e projetos laboratoriais.

O alunado da escola é constituído por moradores da capital e da grande Aracaju; de acordo com informações fornecidas pelo secretário da instituição; depois de Aracaju, a maior parte dos alunos é oriunda do município de Nossa Senhora do Socorro, seguida por Laranjeiras, São Cristóvão, Barra dos Coqueiros e Itaporanga D’ajuda, municípios que compõem a Grande Aracaju.

O processo de matrícula não é feito por seleção, e sim por fila de espera: a Secretaria Estadual de Educação (SEED) disponibiliza uma quantidade de vagas e os interessados são matriculados por ordem de chegada. A prioridade da matrícula é para os alunos oriundos da rede estadual. No entanto, nos últimos anos, houve um crescimento considerável na procura por vagas por alunos oriundos da rede particular de ensino. O secretário acredita que isso tem acontecido pela adesão do sistema de cotas para o ingresso às universidades públicas, já que, estudando todo o ensino médio em escola pública, o aluno tem mais uma chance de concorrer a uma vaga no curso superior.

O Índice de Desenvolvimento da Educação Básica (IDEB) do Atheneu Sergipense, atualizado em 2013, é de 4,6, uma das melhores notas do estado, e segundo informações do secretário da escola, o índice de aprovação em cursos superiores é de $70 \%$ a $75 \%$ do total de alunos concludentes. 


\subsection{COLETA DE DADOS}

Iniciamos o processo de observação a fim de identificar grupos que tivessem quatro membros, duas mulheres e dois homens. As observações aconteciam nos momentos de intervalo, em diferentes pontos da escola (salas de aula, pátio, refeitório, cantina, biblioteca, quadra poliesportiva etc.), com a finalidade de identificar os grupos e suas interações de proximidade. Percebemos que cada ano do ensino médio procura manter relação apenas com os seus membros. Nessa divisão existe uma questão de empatia entre os membros de cada ano. A partir das observações e de interações com os grupos, identificamos como cada grupo/ano identifica o outro e as relações que eles mantêm entre si (Quadro 7.1).

\begin{tabular}{|c|c|c|}
\hline $1^{\circ}$ anos & $2^{\circ}$ anos & $3^{\circ}$ anos \\
\hline $\begin{array}{l}\text { Os } 2^{\circ} \text { anos são imparciais, no } \\
\text { entanto não gostam de se } \\
\text { misturar com os demais. }\end{array}$ & $\begin{array}{l}\text { Os } 1^{\circ} \text { anos são muito } \\
\text { inocentes, não temos } \\
\text { problema com eles e, quando } \\
\text { necessário, interagimos } \\
\text { tranquilamente. }\end{array}$ & $\begin{array}{l}\text { Os } 1^{\circ} \text { anos são inexperientes } \\
\text { e não temos tanta } \\
\text { proximidade, mas nos } \\
\text { relacionamos } \\
\text { necessário. }\end{array}$ \\
\hline $\begin{array}{l}\text { Os } 3^{\circ} \text { anos se acham } \\
\text { melhores que os demais } \\
\text { anos, só porque eles já estão } \\
\text { concluindo o Ensino Médio, } \\
\text { e isso faz com que sejam } \\
\text { muito petulantes, mas, } \\
\text { mesmo assim, mantemos } \\
\text { algum contato com eles. }\end{array}$ & $\begin{array}{l}\text { Os } 3^{\circ} \text { anos, por terem mais } \\
\text { tempo na escola e serem mais } \\
\text { experientes, se acham } \\
\text { melhores que a gente. }\end{array}$ & $\begin{array}{l}\text { Os } 2^{\circ} \text { anos são muito } \\
\text { implicantes para com os } 3^{\circ} \\
\text { anos e vivem em constante } \\
\text { competição, não temos uma } \\
\text { relação muito boa com eles. }\end{array}$ \\
\hline
\end{tabular}

Quadro 7.1 - Panorama de relações entre os grupos de acordo com os alunos.

Constituem a amostra os grupos formados por estudantes do $2^{\circ}$ ano $\mathrm{D}, 3^{\circ}$ ano $\mathrm{A}$ e $3^{\circ}$ ano $\mathrm{B}$, que são compostos por dois homens e duas mulheres cada. Nesse processo de seleção, tomamos como premissa o critério de distância social utilizado por Araujo, Santos e Freitag (2014), em uma escala de proximidade em que o grau 1 é o máximo e o grau 5 é o mínimo de proximidade entre os interlocutores: 
Grau 1 (bastante próximo): os interlocutores fazem parte do mesmo círculo de amigos e conversam com frequência;

Grau 2 (próximo): os interlocutores conversam com frequência, mas não fazem parte do mesmo círculo de amigos;

Grau 3 (próximo): os interlocutores são próximos, mas não conversam com frequência;

Grau 4 (neutro): os interlocutores se conhecem, mas não conversam com frequência; Grau 5 (distante): os interlocutores não se conhecem e só conversam no momento da interação. (ARAUJO, 2014, p. 48)

Utilizamos o $1^{\circ}$ e o $5^{\circ}$ graus de proximidade: no $1^{\circ}$, os interlocutores fazem parte do mesmo grupo de amigos e mantêm contatos diários. Já no $5^{\circ}$ grau de relação, os interlocutores não se conhecem e só conversaram no momento da interação. Por causa do último grau de relação, um dos critérios utilizados para seleção foi de que os quatro membros de cada grupo - nesse caso, dois homens e duas mulheres - fossem amigos entre si e não tivesse nenhuma proximidade com o outro grupo, o que justifica a seleção dos grupos do $2^{\circ}$ e do $3^{\circ}$ anos.

Seguindo o protocolo do procedimento da coleta, depois de explicarmos aos grupos que cada um dos informantes deveria interagir com quatro pessoas, sendo dois do seu grupo de amigos (um homem e uma mulher) e dois que eles não conheciam (um homem e uma mulher), falamos da troca de domínio do tópico, ou seja, ora um interlocutor dominaria o tópico (assunto) da conversa e, em outro momento, haveria a troca desse domínio. Ao final, eles realizariam oito interações de no máximo 40 minutos de gravação cada, totalizando 32 interações. Após esse procedimento, pedimos que eles levassem o Termo de Consentimento para os pais assinarem, autorizando sua participação na pesquisa; também pedimos para que eles preenchessem a ficha social do informante e assinaram o Termo de Assentimento. A Figura 7.2 ilustra a rede de relações dos informantes: a cor azul representa o sexo masculino e a vermelha, o feminino; as linhas mais finas representam relações fracas, entre indivíduos de grupos opostos, e as linhas mais grossas indicam relações fortes entre indivíduos do mesmo grupo. 


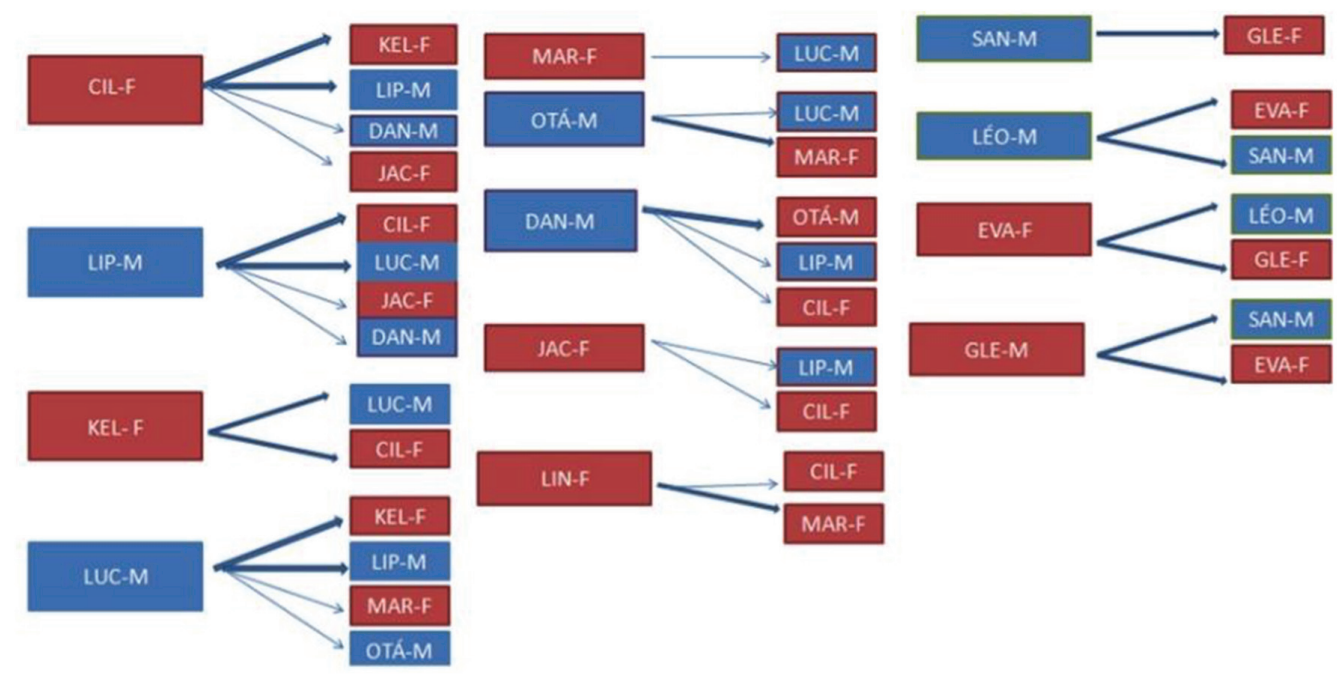

Figura 7.2 - Rede de relações dos informantes.

Diferentemente do modelo da entrevista sociolinguística, que segue um roteiro com perguntas, o modelo de interação conduzida não utiliza roteiros, de modo que, durante a interação, são os próprios informantes que selecionam os tópicos (assuntos) a partir de situações descritas em cartões, conforme a proposta de Araujo, Santos e Freitag (2014). Os assuntos tratados nos cartões são diversificados e abrangem temas como violência, bullying, educação, cotas na universidade, transporte público, meio ambiente, saúde, relacionamento etc. Os temas foram escolhidos e as situações foram formuladas de maneira a contemplar situações de neutralidade, preservação de face positiva e preservação de face negativa (BROWN; LEVINSON, 1987). Ao darmos início às interações, pedimos que o interlocutor, dominador do tópico, escolhesse doze cartões, quatro de cada cor. Depois de selecionar os cartões e identificar qual o assunto que seria abordado em cada um deles, o interlocutor criava microssituações a respeito do que estava proposto e então iniciava a conversa com o seu interlocutor. $\mathrm{O}$ informante dominador do tópico falava sobre os mesmos temas em todas as interações enquanto o domínio do tópico estivesse com ele. O controle do turno permite avaliar como o informante trata do mesmo assunto em função do sexo/ gênero do interlocutor e da distância social que tem com este, o que permite avaliar as estratégias de polidez.

Além das 32 interações conduzidas, realizamos também vinte entrevistas sociolinguísticas, aos moldes labovianos, com um roteiro de perguntas. As duas amostras coletadas constituem o banco de dados Falares Sergipanos (FREITAG, 2013; FREITAG; MARTINS; TAVARES, 2012), contando com a participação de 32 informantes do $1^{\circ}, 2^{\circ}$ e $3^{\circ}$ anos do ensino médio (Quadro 7.2). 


\begin{tabular}{|l|l|l|}
\hline $\begin{array}{l}\text { CÓDIGO DE } \\
\text { INFORMANTES }\end{array}$ & SÉRIE & $\begin{array}{l}\text { TIPO DE } \\
\text { DADO }\end{array}$ \\
\hline ALÊ-M & $3^{\circ}$ ANO & ENTREVISTA \\
\hline AND-M & $3^{\circ}$ ANO & ENTREVISTA \\
\hline ANN-F & $3^{\circ}$ ANO & ENTREVISTA \\
\hline CIL-F & $2^{\circ}$ ANO & INTERAÇÃO \\
\hline DAN-M & $3^{\circ}$ ANO & INTERAÇÃO \\
\hline ELE-F & $3^{\circ}$ ANO & ENTREVISTA \\
\hline EVA-F & $3^{\circ}$ ANO & INTERAÇÃO \\
\hline GLA-M & $2^{\circ}$ ANO & ENTREVISTA \\
\hline GLE-F & $3^{\circ}$ ANO & INTERAÇÃO \\
\hline HEN-M & $1^{\circ}$ ANO & ENTREVISTA \\
\hline JAC-F & $3^{\circ}$ ANO & INTERAÇÃO \\
\hline KEL-F & $2^{\circ}$ ANO & INTERAÇÃO \\
\hline LEN-F & $3^{\circ}$ ANO & ENTREVISTA \\
\hline LEO-M & INTERAÇÃO \\
\hline LET-F & INTERAÇÃO \\
\hline LINA-F & ENTREVISTA \\
\hline
\end{tabular}

\begin{tabular}{|c|c|c|}
\hline LIP-M & $2^{\circ} \mathrm{ANO}$ & $\begin{array}{l}\text { ENTREVISTA/ } \\
\text { INTERAÇÃO }\end{array}$ \\
\hline LUC-M & $2^{\circ}$ ANO & INTERAÇÃO \\
\hline LUI-M & $1^{\circ} \mathrm{ANO}$ & ENTREVISTA \\
\hline MAI-F & $3^{\circ} \mathrm{ANO}$ & ENTREVISTA \\
\hline MAR-F & $5^{\circ} \mathrm{ANO}$ & INTERAÇÃO \\
\hline MAR-M & $2^{\circ} \mathrm{ANO}$ & ENTREVISTA \\
\hline MAY -F & $3^{\circ} \mathrm{ANO}$ & ENTREVISTA \\
\hline MIL-F & $1^{\circ} \mathrm{ANO}$ & ENTREVISTA \\
\hline MIM-F & $1^{\circ} \mathrm{ANO}$ & ENTREVISTA \\
\hline NAT-F & $3^{\circ} \mathrm{ANO}$ & ENTREVISTA \\
\hline NÉL-M & $1^{\circ} \mathrm{ANO}$ & ENTREVISTA \\
\hline OTÁ-M & $3^{\circ} \mathrm{ANO}$ & INTERAÇÃO \\
\hline SAND-M & $3^{\circ} \mathrm{ANO}$ & INTERAÇÃO \\
\hline SUS-F & $3^{\circ} \mathrm{ANO}$ & ENTREVISTA \\
\hline TIA-M & $3^{\circ} \mathrm{ANO}$ & ENTREVISTA \\
\hline VIN-M & $1^{\circ} \mathrm{ANO}$ & ENTREVISTA \\
\hline
\end{tabular}

Quadr• 7.2 - Relação de indivíduos, série escolar e tipo de coleta constitutiva da amostra.

As documentações orais foram transcritas e realizamos a identificação dos fenômenos sob análise; todas as ocorrências dos fenômenos de variação na realização oclusiva/africada seguinte ao glide palatal e expressão da primeira pessoa do plural com sujeito explícito foram computadas; no fenômeno do alçamento, foram consideradas as primeiras quarenta ocorrências de palavras paroxítonas ou proparoxítonas com as vogais /e/ e /o/. Os fenômenos foram codificados quanto 
às variáveis linguísticas específicas e às variáveis sociais e pragmáticas, comuns a todos (sexo/gênero, bairro de residência, tipo de coleta, distância social, simetria da interação e indivíduos) e submetidos, individualmente, à análise estatística do programa GoldVarb X (SANKOFF; TAGLIAMONTE; SMITH, 2005).

\subsection{RESULTADOS}

As frequências de cada um dos fenômenos (Tabela 7.1) sinalizam para a polarização da forma a gente e da realização africada das oclusivas seguintes ao glide palatal, e para a variabilidade do alçamento das vogais médias, na amostra sob análise.

\begin{tabular}{|l|l|l|}
\hline Fenômeno & Aplicação/total & Percentual \\
\hline Alçamento de vogais médias & $1040 / 2022$ & $51,4 \%$ \\
\hline Realização da 1ª pessoa plural (a gente) & $744 / 928$ & $83,4 \%$ \\
\hline Realização africada de oclusivas seguintes ao glide & $256 / 2504$ & $10,2 \%$ \\
\hline
\end{tabular}

Tabela 7.1 - Frequências dos fenômenos.

Para cada fenômeno, o modelo foi submetido à análise binomial one-level do GoldVarbX, que tem por objetivo mostrar a proporção de aplicação da regra em cada célula formada pela combinação dos fatores e a proporção preditiva calculada para o modelo construído. Os resultados são apresentados em um diagrama de dispersão (scattegrams, Figura 7.3). O tamanho de cada ponto é proporcional ao número de ocorrências em cada célula (TAGLIAMONTE, 2006).

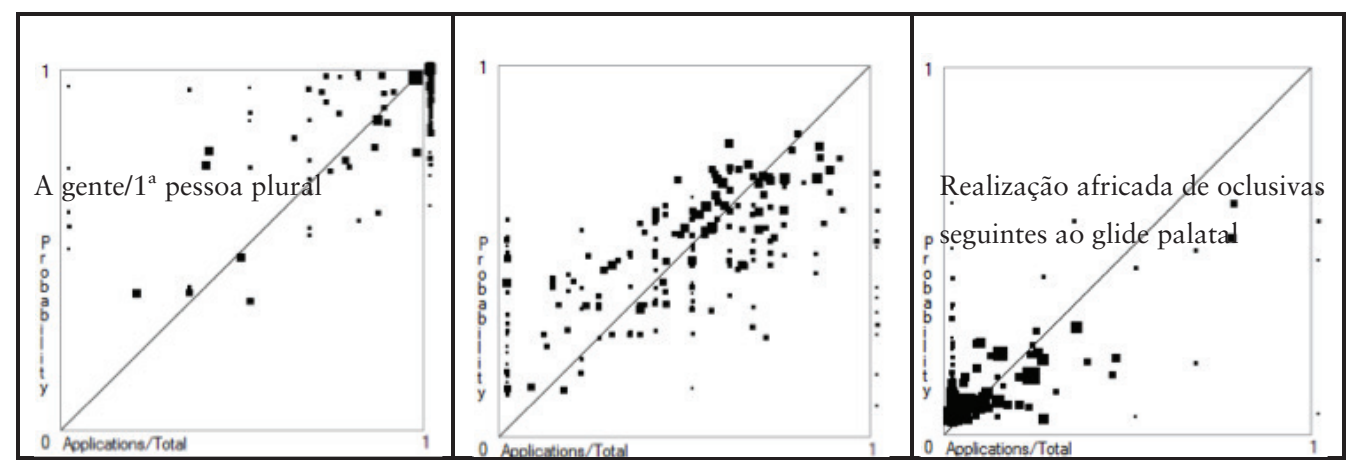

Alçamento de vogais médias

Figura 7.3 - Dispersões dos fenômenos. 
As dispersões (scattegrams) na Figura 3 mostram o comportamento diferenciado dos fenômenos. Os dados da realização africada das oclusivas seguintes ao glide concentram-se na extremidade diagonal próxima ao zero (não aplicação da regra) e em pontos de tamanho superior aos pontos dos demais fenômenos, sugerindo a interação entre. Os dados da realização da $1^{a}$ pessoa do plural se concentram na extremidade diagonal próxima ao 1 (aplicação da regra; valor de aplicação: a gente), e os dados do alçamento distribuem-se próximos à linha diagonal, em posição intermediária entre a aplicação e a não aplicação da regra.

A distribuição de frequências pelos 32 indivíduos (Figura 7.3) controlados na amostra sob análise traz mais indícios do comportamento dos fenômenos quanto à avaliação social: todos os indivíduos realizam alçamento e não alçamento, reforçando o comportamento de indicador do fenômeno. $\mathrm{Na}$ expressão da $1^{\mathrm{a}}$ pessoa, catorze dos 32 indivíduos realizam categoricamente a forma a gente, e sete não realizam ocorrências da forma africada, sendo estes moradores de Aracaju, o que reforça um comportamento de estereótipo para a variante.

Foram realizadas análises binomial up and down com cada um dos fenômenos, excluindo-se o controle do fator indivíduos, por conta da sobreposição a outros fatores de natureza social. Os resultados convergem para a avaliação social de cada um dos fenômenos.

\subsubsection{EXPRESSÃO DA $1^{a}$ PESSOA DO PLURAL}

Três fatores são estatisticamente significativos no condicionamento da expressão da $1^{\text {a }}$ pessoa do plural na amostra analisada (level $0=0,834 \log =$ -417.046), um de natureza linguística e dois de natureza pragmática.

O escopo da referência da forma de $1^{a}$ pessoa do plural é uma variável que foi controlada por Lopes (1998), Silva (2004), Mendonça (2012), Santos (2014), entre outros, e tem se mostrado atuante no condicionamento do fenômeno. O controle visa identificar, por pistas contextuais, o escopo da referência do sujeito da $1^{a}$ pessoa do plural, em uma escala que vai do mais ao menos específicos. Escopos mais específicos referem-se ao sujeito falante e interlocutor presentes no momento da interação (eu + você-s), como em (3).

(3) EVA-F: como naquele dia...

LEO-M: e não pode... como naquele dia que a gente tava voltando da UNIT e o ônibus tava lotadíssimo... [...] (LEO-M I) 





Há caso de escopo de referência em que o interlocutor incluído está ausente no momento da interação (eu + ele), como em (4), e (eu +eles), em (5).

(4) CIL-F: lembro que era no mesmo bairro que eu morava aí eu peguei a gente namorava já há um tempinho né? escondido aí a gente tava lá ai a gente saia né? do colégio...[...] (CIL-F I)

(5) DAN-M: e em relação à família você viaja muito com sua família? você é muito unido? pra onde vocês vão quando viajam?

OTA-M: rapaz minha família a gente costuma sair geralmente sábado domingo assim para ir para algum lugar à praia em casa visitar os avós viaja assim pra outros lugares [...] (OTA-M I)

O escopo menos específico refere-se a sujeito genérico (eu + todos), em (6), ou indeterminados (eles), em (7).

(6) LIP-M: a alimentação ela influencia muito na nossa vida porque não só em termos que vai deixar a gente forte e saudável mas também que isso faz com que a gente uma estética [...] (LIP-M I)

(7) GLE-F: num tem num tem manutenção

EVA-F: e a gente que que elege

GLE-F: é

EVA-F: a gente não porque eu mesmo num voto num filho do <capiroto>> desse ((RISOS)) é quem vota

GLE-F: é (EVA-F I)

Os resultados apontam o predomínio da forma a gente em todos os contextos, no entanto os pesos relativos sinalizam a recorrência da forma em contextos de referência que excluem o interlocutor do contexto da interação (eu + ele, 0,64; eu + eles, 0,68$)$.

\begin{tabular}{|l|l|l|l|}
\hline Escopo da referência & Aplicação & Percentual & Peso relativo \\
\hline Eu + você & $94 / 140$ & $67 \%$ & 0,30 \\
\hline Eu + vocês & $122 / 150$ & $81 \%$ & 0,41 \\
\hline Eu + ele & $108 / 115$ & $93 \%$ & 0,64 \\
\hline Eu + eles & $313 / 335$ & $93 \%$ & 0,68 \\
\hline Eu + todos & $130 / 180$ & $72 \%$ & 0,31 \\
\hline Eles & $5 / 6$ & $83 \%$ & 0,52 \\
\hline Input: 0.897 Log = -323.564 Sig.= 0,017 & \\
\hline
\end{tabular}

Tabela 7.2 - Escopo da referência no uso da forma $a$ gente. 
A variável simetria/assimetria da interação visa controlar os efeitos do sexo/ gênero como estratégias de polidez, envolvendo o controle do tópico (quem introduz o assunto e o sexo/gênero propriamente. Holmes (1998) postula que relações entre pares $(\mathrm{H}-\mathrm{H}, \mathrm{M}-\mathrm{M})$ são mais espontâneas e produtivas, e que as interações entre pessoas de sexo/gênero opostos (H-M, M-H) são mais breves e formais, pois relações entre pares deixariam os interlocutores mais à vontade, enquanto as relações de sexo/gênero oposto tenderiam a ser mais controladas. Esta variável foi controlada por Santos (2014).

\begin{tabular}{|l|l|l|l|}
\hline Simetria & Aplicação & Percentual & Peso relativo \\
\hline H X H & $153 / 180$ & $85 \%$ & 0,60 \\
\hline H X M & $176 / 263$ & $66 \%$ & 0,21 \\
\hline M X H & $148 / 156$ & $94 \%$ & 0,80 \\
\hline M X M & $297 / 329$ & $90 \%$ & 0,54 \\
\hline Input: 0,897 Log = -323.564 Sig. $=0,017$ \\
\hline
\end{tabular}

Tabela 7.3 - Relação de simetria/assimetria entre sexos no uso da forma a gente.

Embora o fator sexo/gênero não tenha sido selecionado como estatisticamente significativo na amostra, a simetria/assimetria da interação o foi, possivelmente pela imbricação de fatores envolvidos no seu controle. As interações assimétricas cujo tópico foi conduzido por homens tiverem a maior restrição da forma a gente, com peso relativo de 0,20 , sugerindo que as estratégias de preservação de face, na linha do que sugere Holmes (1998), são realizadas pela variante nós.

Última variável selecionada como estatisticamente significativa, o tipo de coleta permite avaliar os efeitos da formalidade/informalidade da situação. A forma a gente, embora predomine em ambos os tipos de coleta, se mostra mais produtiva nas situações de entrevista, com peso relativo de 0,63 .

\begin{tabular}{|l|l|l|l|}
\hline Tipo de coleta & Aplicação & Percentual & Peso relativo \\
\hline Entrevista & $249 / 269$ & $92 \%$ & 0,63 \\
\hline Interação & $525 / 659$ & $79 \%$ & 0,44 \\
\hline Input: 0,897 Log $=-323.564$ & $\mathrm{Sig} .=0,017$ \\
\hline
\end{tabular}

Tabela 7.4 - Variante a gente em relação ao tipo de coleta.

Este resultado contraria aquele obtido por Santos (2014), que tomamos por hipótese: esperávamos que nas interações, o uso da forma a gente fosse 
preferido pelos indivíduos da amostra, por esta ter sido coletada no modelo locutor/interlocutor, que propicia interações mais espontâneas, diferentemente da situação de entrevista (entrevistador/entrevistado), mais distante e hierarquizada, que pode levar a uma interação mais monitorada, formal. Por outro lado, a não confirmação da hipótese reforça o comportamento de marcador: a gente está ocupando espaço em contextos mais formais, em que canonicamente haveria a ocorrência da forma nós.

\subsubsection{ALÇAMENTO DAS VOGAIS MÉDIAS}

O alçamento das vogais médias a altas, na amostra analisada, apresentou três fatores estatisticamente significativos (input $=0,514, \log$ likelihood $=-1400.712$ ), todos de natureza linguística, reforçando mais uma vez a não avaliação social do fenômeno, um indicador.

Quanto ao tipo de vogal, primeiro fator selecionado, observamos que o fenômeno ocorre com maior frequência diante da vogal /e/ do que /o/, resultado semelhante ao obtido por Cardoso (1999), com dados da região Nordeste.

\begin{tabular}{|l|l|c|c|}
\hline Tipo de vogal & Aplicação/Total & $\%$ & Peso relativo \\
\hline /e/ & $792 / 1318$ & $60,1 \%$ & 0,59 \\
\hline /o/ & $248 / 703$ & $35,3 \%$ & 0,37 \\
\hline \multicolumn{2}{|c|}{ Input 0,511 Log $=-1305.358$} & Sig. $=0,000$ \\
\hline
\end{tabular}

Tabela 7.5 - Alçamento das vogais médias e altas quanto ao tipo de vogal.

Por outro lado, Battisti (1993), com dados do Rio Grande do Sul, identifica maior tendência ao alçamento na vogal /o/. Tais resultados reforçam que o alçamento de vogais média tem valor dialetal

Em relação à posição da sílaba tônica, os resultados apontam a restrição do alçamento em posição postônica (palavras proparoxítonas), com peso relativo de 0,16 .

\begin{tabular}{|l|l|c|c|}
\hline Posição & Aplicação/Total & $\%$ & Peso relativo \\
\hline Pretônicas & $1026 / 1921$ & $53,4 \%$ & 0,52 \\
\hline Postônicas & $369 / 841$ & $13,9 \%$ & 0,16 \\
\hline \multicolumn{2}{|r|}{ Input 0,511 Log $=-1305.358 \mathrm{Sig},=0,000$} \\
\hline
\end{tabular}

Tabela 7.6 - Alçamento das vogais médias e altas quanto à posição da silaba tônica.

Quanto à categoria gramatical, o alçamento é favorecido nos nomes e desfavorecido nos verbos. 


\begin{tabular}{|l|l|c|c|}
\hline Categorias gramaticais & Aplicação/Total & $\%$ & Peso relativo \\
\hline Nome & $671 / 1181$ & $56,8 \%$ & 0,56 \\
\hline Verbos & $369 / 841$ & $43,9 \%$ & 0,41 \\
\hline \multicolumn{2}{|c|}{ Input 0,511 Log $=-1305.358$ Sig. $=0,000$} \\
\hline
\end{tabular}

Tabela 7.7 - Alçamento das vogais médias e altas quanto à categoria gramatical.

Os resultados do alçamento de vogais médias reforçam o comportamento de indicador na amostra analisada: está presente na fala de todos os indivíduos e é motivado basicamente por fatores de natureza interna, como o tipo da vogal, a posição da sílaba tônica e a categoria gramatical da palavra, seguindo a tendência de outros estudos da mesma zona dialetal.

\subsubsection{REALIZAÇÃO AFRICADA DE OCLUSIVAS ALVEOLARES SEGUINTES AO GLIDE}

Do total de palavras, 68\% (1731/2504) são ocorrências de muito e suas flexões, que, por conta da alta frequência, foram excluídas. A análise binomial up and down do conjunto das outras palavras apontou influência de dois fatores de natureza linguística: o vozeamento e o grau dos nomes, respectivamente $1^{\circ}$ e $4^{\circ}$ na ordem de cinco fatores apontados como estatisticamente significativos (level 0 $=0,89, \log =-273,956)$.

\begin{tabular}{|l|l|l|l|}
\hline Ambiente & Apl./total & Percentual & Peso Relativo \\
\hline /t/ & $39 / 649$ & $6 \%$ & 0,40 \\
\hline$/$ d/ & $48 / 140$ & $34 \%$ & 0,87 \\
\hline Total & $87 / 789$ & $11 \%$ & - \\
\hline Input $=0,951 \mathrm{Log}=-173,713 \mathrm{Sig} .=0.000$ \\
\hline
\end{tabular}

Tabela 7.8 - Atuação do vozeamento na realização africada de oclusivas seguintes ao glide.

O ambiente vozeado é mais propício à realização africada do que o ambiente desvozeado, mais propício à realização oclusiva.

As palavras de base nominal que são passíveis de derivação com o sufixo -inho (grau diminutivo) também se mostram mais sensíveis à realização africada do que as palavras de grau normal. 


\begin{tabular}{|l|l|l|l|}
\hline “Grau” das palavras & Apl./total & Percentual & Peso Relativo \\
\hline Normal & $70 / 551$ & $13 \%$ & 0,48 \\
\hline Diminutivo & $5 / 14$ & $36 \%$ & 0,93 \\
\hline Total & $490 / 565$ & $13 \%$ & - \\
\hline Input = 0,951 Log = -173,713 Sig. $=0.000$ & \\
\hline
\end{tabular}

Tabela 7.9 - Atuação do gra nas palavras de base nominal na realização africada de oclusivas seguintes ao glide.

O resultado nesta amostra segue o padrão identificado anteriormente, de tendência à realização africada nas palavras com sufixo -inho, o que reforça a necessidade de averiguar a interação dos processos fonológicos de nasalização e palatalização, como já apontado por Freitag (2015).

Quanto ao local de residência, os alunos que estudam no Atheneu Sergipense são oriundos de diferentes municípios da região conhecida por Grande Aracaju. $\mathrm{Na}$ amostra constituída, no entanto, os informantes residem em Aracaju, Nossa Senhora do Socorro, São Cristóvão e Barra dos Coqueiros. Estes municípios constituem a região metropolitana de Aracaju, reconhecida oficialmente por meio da Lei Complementar Estadual no 25/1995. Nos últimos anos, a região metropolitana vem passando por um significativo aumento populacional, que levou à criação de zona de expansão na região limítrofe entre Aracaju e São Cristóvão. O aumento populacional decorre de migrantes das regiões rurais do próprio estado de Sergipe, assim como de Alagoas, e do norte e nordeste da Bahia.

Inicialmente, controlamos o município de residência dos informantes como uma variável; como os resultados foram polarizados, com forte restrição à variante africada em Aracaju, amalgamamos os dados dos demais municípios sob o rótulo de região metropolitana. Do ponto de vista socioeconômico, há uma distinção bem clara entre Aracaju e os demais municípios. Por exemplo, o Índice de Desenvolimento Humano (IDH) de Aracaju é de 0,770, enquanto o dos demais municípios está na casa dos 0,60 (Barra dos Coqueiros 0,649; Nossa Senhora do Socorro 0,664 e São Cristóvão 0,662).

\begin{tabular}{|l|l|l|l|}
\hline Localidade & Apl./total & $\%$ & Peso Relativo \\
\hline Aracaju & $14 / 418$ & $3 \%$ & 0,30 \\
\hline Região metropolitana & $73 / 372$ & $20 \%$ & 0,72 \\
\hline Input = 0,951 Log = -173,713 Sig. $=0.000$ \\
\hline
\end{tabular}

Tabela 7.10 - Atuação da localidade de residência na realização africada de oclusivas seguintes ao glide. 
A realização africada é influenciada pelo local de residência dos informantes, com 0,72 na região metropolitana, e desfavorecida, com 0,30, em Aracaju. Em nossas observações, identificamos que os alunos fazem distinção entre morar em Aracaju e morar na região metropolitana. Em uma sondagem, um dos informantes que residia na Taiçoca, bairro de Nossa Senhora do Socorro, disse, em tom jocoso, que estava lá "só até o apartamento da 13 ficar pronto" (13 de Julho, bairro de classe média alta nas adjacências da instituição).

Segundo Brown e Levinson (1987), a distância social é um fator significativo no contexto de polidez, uma vez que a relação existente entre os interlocutores influenciará na escolha linguística e na qualidade da interação. Esse comportamento social contribui para a tendência de o falante ser mais polido com quem tem menos familiaridade, pois quando interagimos com alguém com quem não temos proximidade, tendemos a um maior monitoramento da nossa fala.

A manifestação da polidez pode se dar pelo menor percentual de realização africada, considerando que a variante é um estereótipo. Do mesmo modo, quando os informantes são próximos um do outro, é possível que se monitorem menos e deixem emergir a variante, por conta da informalidade e familiaridade.

\begin{tabular}{|l|l|l|l|}
\hline Distância Social & Apl./total & $\%$ & Peso Relativo \\
\hline Próximo & $77 / 403$ & $19 \%$ & 0,69 \\
\hline Distante & $26 / 237$ & $3 \%$ & 0,21 \\
\hline Input = 0,951 Log $=-173,713$ & Sig. $=0.000$ \\
\hline
\end{tabular}

Tabela 7.11 - Atuação da distância social na realização africada de oclusivas seguintes ao glide.

Os resultados apontam a tendência à realização africada nas relações mais próximas. Nas interações em que os participantes não têm proximidade, houve maior monitoramento do uso da variante africada; por não se conhecerem antes, os interlocutores talvez tenham tentado ao máximo mostrar a sua face positiva com o intuito, mesmo que inconsciente, de ter uma aprovação positiva, ou seja, de ter uma imagem socialmente prestigiada, já que as evidências sugerem que a variante é considerada um estereótipo.

\subsection{CONSIDERAÇÕES FINAIS}

A análise de três fenômenos variáveis do português - a realização africada de oclusivas alveolares seguintes ao glide palatal, a variação na primeira pessoa do plural e o alçamento de vogais médias a altas - em uma amostra constituída com vistas ao controle de variáveis pragmáticas que captem as nuanças de polidez, 
evidenciou que o modo como uma variante linguística é avaliada socialmente por um indivíduo ou por determinado grupo pode implicar na preservação da face, por meio do monitoramento linguístico.

Além disso, a tensão entre a dinâmica da estrutura da língua e a dinâmica social, especialmente o papel normatizador da escola, fica evidente não só pela distribuição de frequências dos fenômenos sensíveis à avaliação social, como a variação na realização de oclusivas dentais seguintes ao glide palatal e a variação na primeira pessoa do plural, mas pelo testemunho dos próprios falantes.

\subsection{REFERÊNCIAS}

ABAURRE-GNERRE, M. B. M. Processos fonológicos segmentais como índices de padrões prosódicos diversos nos estilos formal e casual do português do Brasil. Cadernos de Estudos Linguísticos, Campinas, v.2; p. 23-44, 1981.

ALVES, E. M. S. O Atheneu Sergipense: traços de uma história. Revista do Instituto Histórico e Geográfico de Sergipe, Aracaju, n. 34, p. 133-152, 2005.

ARAUJO, A. S. Você me faria um favor?: o futuro do pretérito e a expressão de polidez. Dissertação (Mestrado em Letras) - Programa de Pós-Graduação em Letras, Universidade Federal de Sergipe, São Cristóvão, 2014.

ARAUJO, A; SANTOS, K. C.; FREITAG, R. M. K. Redes sociais, variação linguística e polidez: procedimentos de coleta de dados. In: FREITAG, R. M. K. (Org.). Metodologia de coleta e manipulação de dados em sociolinguística, São Paulo: Blucher, 2014. p. 99-116.

BATTISTI, E. Elevação das vogais médias pretônicas em sílaba inicial de vocábulo na fala gaúcha. Dissertação (Mestrado em Letras: Língua Portuguesa) - Programa de Pós-Graduação em Letras, Universidade Federal do Rio Grande do Sul, Porto Alegre, 1993.

BISOL, L. Harmonia vocálica: uma regra variável. Tese (Doutorado em Linguística) - Programa de Pós-Graduação em Linguística, Universidade Federal do Rio de Janeiro, Rio de Janeiro, 1981.

BROWN, P.; LEVINSON, S. Politeness: some universals in language usage. Cambridge: Cambridge University Press, 1987.

CAMPOS, E. A. O uso dos pronomes nós e a gente no gênero entrevista da mídia televisiva: uma análise do português culto falado em Belém. In: Anais do I SIMELP, São Paulo: Universidade de São Paulo, 2008.

CARDOSO, S. A. As Vogais médias pretônicas no Brasil: uma visão diatópica. In: AGUILERA, V. de A. (Org.). Português do Brasil: estudos fonéticos e fonológicos. Londrina: EdUEL, 1999. p. 93-108. 
FREITAG, R. M. K. Banco de dados falares sergipanos. Working Papers em Linguística, Florianópolis, v. 14, n. 2, p. 156-164, 2013.

- Socio-stylistic aspects of linguistic variation: schooling and monitoring effects. Acta Scientiarum. Language and Culture, Maringá, v. 37, n. 2, p. 127-136, 2015.

FREITAG, R. M. K.; MARTINS, M. A.; TAVARES, M. A. Bancos de dados sociolinguísticos do português brasileiro e os estudos de terceira onda: potencialidades e limitações. Alfa: Revista de Linguística, São Paulo, v. 56, p. 917-944, 2012.

HOLMES, J. Complimenting: A positive politeness strategy. In: COATES, J. (Ed.). Language and gender: a reader. Oxford: Blackwell, 1998. p. 100-120.

LABOV, W. Padrões sociolinguísticos. Tradução de Marcos Bagno, Marta Scherre e Caroline Cardoso. São Paulo: Parábola Editorial, 2008.

LOPES, C. R. S. Nós e a gente no português falado culto do Brasil. Revista DELTA, São Paulo, v. 2, n. 14, p. 405-422, 1998.

MENDONÇA, A. K. Nós e a gente na cidade de Vitória: análise da fala capixaba. Revista percursos linguísticos, Vitória, v. 2, n. 4, p. 1-18, 2012.

SANKOFF, D.; TAGLIAMONTE, S.; SMITH, E. Goldvarb X: A variable rule application for Macintosh and Windows. Department of Linguistics of University of Toronto. Ottawa: Department of Mathematics of University of Ottawa, 2005.

SANTOS, K. C. Estratégias de polidez e a variação de nós vs. a gente na fala de discentes da Universidade Federal de Sergipe. Dissertação (Mestrado em Letras) - Programa de Pós-Graduação em Letras, Universidade Federal de Sergipe, São Cristóvão, 2014.

SILVA, I. De quem nós/a gente está (mos) falando afinal?: uma investigação sincrônica da variação entre nós e a gente como estratégias de designação referencial. Dissertação (Mestrado em Linguística) - Programa de Pós-Graduação em Linguística, Universidade Federal de Santa Catarina, Florianópolis, 2004.

TAGLIAMONTE, S. A. Analysing sociolinguistic variation. Cambridge University Press, 2006.

ZILLES, A. M. S. The development of a new pronoun: the linguistic and social embedding of a gente in Brazilian Portuguese". Language Variation and Change, Cambridge, v. 1, n. 17, p. 19-53, 2005. 
